\title{
Improving Li Plating Behaviors Through Cu-Sn Alloy-Coated Current Collector for Dendrite-Free Lithium Metal Anodes
}

\author{
Yifeng Cheng ${ }^{1,2} \cdot \mathrm{Xi} \mathrm{Ke}^{1,2} \cdot$ Zhicong Shi $^{1,2}$
}

Received: 21 October 2019 / Revised: 20 December 2019 / Published online: 12 March 2020

(C) The Chinese Society for Metals (CSM) and Springer-Verlag GmbH Germany, part of Springer Nature 2020

\begin{abstract}
Alloy anode with good reversibility of lithium plating/stripping and long cycling stability is considered as promising anode materials. Here, $\mathrm{Cu}-\mathrm{Sn}$ alloy is used as the substrate for $\mathrm{Li}$ deposition to induce the most densely packed arrangement of $\mathrm{Li}$ atoms, thus presenting high lithiophilicity and improving $\mathrm{Li}$ plating behaviors. $\mathrm{The}_{\mathrm{LiFePO}}$-based full cell with the asprepared dendrite-free Li metal anode retained at $85 \mathrm{mAh} \mathrm{g}^{-1}$ with a high coulombic efficiency of $99.5 \%$ after 300 cycles, presenting a capacity retention of $79.4 \%$. This strategy provides a new perspective to structure dendrite-free $\mathrm{Li}$ anode for the next-generation high-energy density batteries.
\end{abstract}

Keywords Li metal anodes $\cdot$ Dendrite-free $\cdot$ Composite electrode $\cdot$ Lithiophilic surface

\section{Introduction}

Metallic lithium electrode has been regarded as one of the most promising anode materials for high-energy batteries due to its high specific capacity $\left(3860 \mathrm{mAh} \mathrm{g}^{-1}\right)$ and lowest potential (-3.04 V vs SHE) [1,2]. However, Li metal anode suffers from several serious issues, including severe growth of dendritic or mossy Li caused by non-uniform Li deposition, which results in internal short circuit and safe accidents [3]; instable solid electrolyte interphase (SEI) promotes electrolyte consumption and electrode pulverization due to the high reactivity of Li metal, which leads to reduced coulombic efficiency (CE) and fast capacity decay upon cycling [4]. To date, considerable efforts have been devoted to solving these issues, including development of protective layers to reduce parasitic side reactions [5], adding electrolyte additives to produce stable SEI [6], employing solid electrolyte

Available online at https://link.springer.com/journal/40195.

Zhicong Shi

zhicong@gdut.edu.cn

1 Smart Energy Research Centre, School of Materials and Energy, Guangdong University of Technology, Guangzhou 510006, China

2 Guangdong Engineering Technology Research Center for New Energy Materials and Devices, Guangzhou 510006, China to improve safety [7], constructing three-dimensional (3D) current collectors to reduce the effective current density during charge/discharge process [8,9], modifying lithiophilic phases to decrease Li nucleation overpotential [10], and designing composite lithium electrodes based on Li melt infusion to alleviate electrode volume change during Li plating/stripping [11]. Among these approaches, using alloy anodes is a hopeful strategy for stabilizing Li metal anodes (LMAs) owing to the following advantages: (1) enhanced stability of metal-containing SEI and a smooth Li deposition morphology [12, 13]; (2) Li-poor alloy with high electronic/ ionic conductivity can act as an excellent current collector and then host for Li plating [14]. Notably, Nazar and coworkers designed a Li- $X$ alloy ( $X=\mathrm{In}, \mathrm{Zn}$ and $\mathrm{Bi}$ ) SEI layer to guide uniform Li nucleation and deposition [14]. Luo's group reported the use of $\mathrm{Cu}-\mathrm{Zn}$ alloy as artificial defects to lower the deposition interface energy for stable LMAs [15]. However, its high cost, sophisticated process and poor structure stability hinder its large-scale application and further development.

In this work, we report a facile approach to construct the lithiophilic nature of substrate to depress Li dendrites growth for safe and high-performance LMAs. This process is simply done by electrodeposition of $\mathrm{Cu}-\mathrm{Sn}$ alloy on $\mathrm{Cu}$ foam. In addition, the lattice orientation of $\mathrm{Sn}$ is investigated, and it is found that it could enhance affinity between current collector and $\mathrm{Li}$ metal, achieving dendrite-free $\mathrm{Li}$ 
deposition. The as-prepared LMAs show high CE and long cycling life in $\mathrm{LiFePO}_{4}$-based full cells.

\section{Experimental}

The synthesis of $\mathrm{Cu}-\mathrm{Sn}$-decorated $\mathrm{Cu}$ foam combined preparation of polystyrene (PS) template, $\mathrm{Cu}-\mathrm{Sn}$ alloy electroplating, and a thermal annealing treatment. The clean $\mathrm{Cu}$ foam (CF) substrates were immersed in PS solution at $70{ }^{\circ} \mathrm{C}$ for $2 \mathrm{~h}$. After drying, the PS template/CF was prepared and used as the working electrode for electroplating of $\mathrm{Cu}-\mathrm{Sn}$ alloy. The electrolyte composition consisted of $33 \mathrm{mM} \mathrm{Cu}_{2} \mathrm{P}_{2} \mathrm{O}_{7}$, $12 \mathrm{mM} \mathrm{Sn}_{2} \mathrm{P}_{2} \mathrm{O}_{7}, 0.33 \mathrm{M} \mathrm{K}_{4} \mathrm{O}_{7} \mathrm{P}_{2}$, and $0.20 \mathrm{M} \mathrm{K}_{2} \mathrm{HPO}_{4}$. The electroplated electrodes were thoroughly rinsed with dichloromethane to remove the template. Finally, the electrodes were annealed at $260{ }^{\circ} \mathrm{C}$ for $2 \mathrm{~h}$.

Electrochemical performances of the as-prepared electrodes were evaluated by CR2032-type coin cells using Celgard as separator and $\mathrm{Li}$ foil or $\mathrm{LiFePO}_{4}$ cathodes as counter electrode. The $\mathrm{LiFePO}_{4}$ cathodes were composed of $80 \%$ $\mathrm{LiFePO}_{4}, 10 \%$ Super-P, and 10\% PVDF binder. The electrolyte was $1 \mathrm{M}$ LiTFSI in dioxolane (DOL) and dimethoxyethane $(1: 1, \mathrm{v} / \mathrm{v})$ with $1 \mathrm{wt} \% \mathrm{LiNO}_{3}$. The CE of cells was characterized by discharging $1 \mathrm{mAh} \mathrm{cm}{ }^{-2}$ and then charging to $1 \mathrm{~V}$ at a current density of $1.5 \mathrm{~mA} \mathrm{~cm}^{-2}$. Galvanostatic cycling was carried out between $2.4 \mathrm{~V}$ and $4.2 \mathrm{~V}$ at $5 \mathrm{C}$.

\section{Results and Discussion}

Figure 1a shows the morphology of $\mathrm{Cu}$ foam, which is composed of a network of 3D interconnected ligaments, and demonstrates a rough surface of ligament consisted of irregularly shaped micro-size granules (inset in Fig. 1a). After electrodeposition of alloy on $\mathrm{Cu}$ foam, the $\mathrm{Cu}-\mathrm{Sn}$ alloy with quasi-ordered pores was successfully coated on $\mathrm{Cu}$ foam surface, and Sn particles were uniformly grown on the substrate (Fig. 1b). TEM and the corresponding energydispersive $\mathrm{X}$-ray spectroscopy element mapping results show
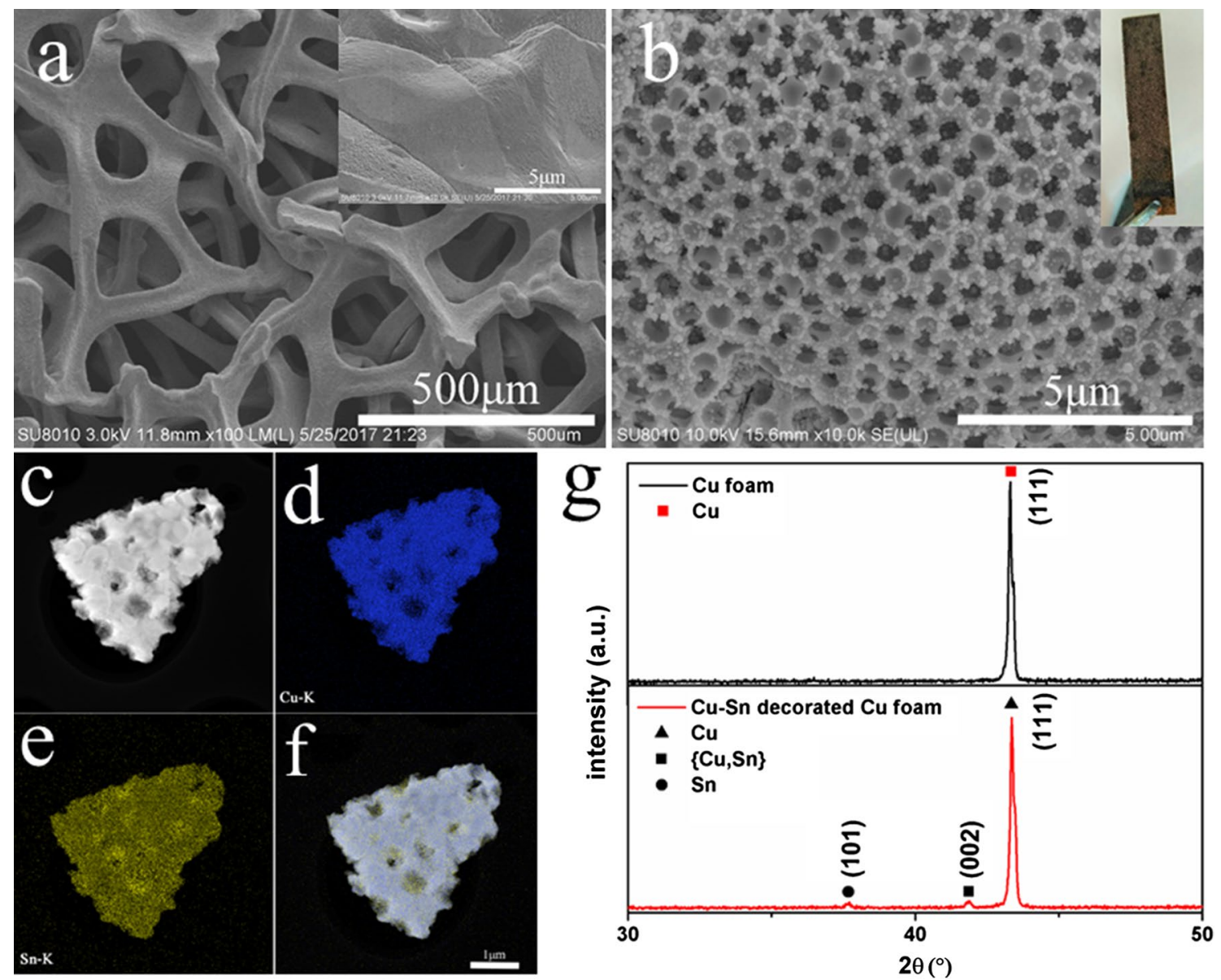

Fig. 1 SEM images of a $\mathrm{Cu}$ foam $\mathbf{b} \mathrm{Cu}-\mathrm{Sn}$-decorated $\mathrm{Cu}$ foam (inset showing the morphology of $\mathrm{Cu}$ foam at high magnification and the digital photograph of $\mathrm{Cu}-\mathrm{Sn}$-decorated $\mathrm{Cu}$ foam). $\mathbf{c}$ TEM image and the corresponding $\mathbf{d ~ C u}, \mathbf{e} \mathrm{Sn}, \mathbf{f}$ overlapping element mapping images. $\mathbf{g} \mathrm{XRD}$ patterns of $\mathrm{Cu}$ foam and $\mathrm{Cu}-\mathrm{Sn}$-decorated $\mathrm{Cu}$ foam 
that the distribution of $\mathrm{Sn}$ is around the surface layer while the distribution of $\mathrm{Cu}$ is around the central cores (Fig. 1c-f), which illustrated that metallic $\mathrm{Sn}$ was grown on $\mathrm{Cu}-\mathrm{Sn}$ alloy substrate. XRD patterns of as-prepared electrodes show new diffraction peak of $S n$ (the $\{101\}$ family of planes) and $\mathrm{Cu}-\mathrm{Sn}$ alloy compared to $\mathrm{Cu}$ foam electrode (Fig. $1 \mathrm{~g}$ ), which is consistent with the above results.

The morphologies that $\mathrm{Li}$ electrodeposits form during the earliest stages of electrodeposition are known to play a critical role in the recharge of Li metal battery. The initial morphology evolution of Li deposition on different current collectors was investigated through SEM. It could be seen that Li deposition was guided by uniform Sn particles from Fig. 2a-c, forming a smooth Li coating layer on the substrate. While Li clusters grown on bare $\mathrm{Cu}$ foam, then clusters transformed into dendrites (Fig. 2d-f). Reducing the $\mathrm{Li}$ nucleation barrier could result in smooth $\mathrm{Li}$ deposition, so that Li dendrites were inhibited and electrochemical performance of Li anode was improved [16, 17]. Bulk Li deposited along the most stable (110) direction, which presented lowest nucleation barrier due to the $\{110\}$ family of planes, had the most densely packed arrangement of atoms [18]. Electrodeposition on a heterogeneous substrate was preceded by under-potential deposition that affected by lattice mismatch between the substrate and the Li metal. Sn component in as-prepared electrode alloyed with lithium to form $\mathrm{Li}-\mathrm{Sn}$ alloy layer, which alleviated lattice mismatch between the substrate and subsequent Li deposition. Moreover, the Sn (101) face could serve as appropriate orientation for enhancing lattice coincidence with the $\mathrm{Li}$ (110) plane, enhancing affinity between current collector and Li metal, achieving dendrite-free Li deposition.

Electrochemical performance of $\mathrm{Cu}-\mathrm{Sn}$-decorated $\mathrm{Cu}$ foam and $\mathrm{Cu}$ foam electrode is demonstrated in Fig. 3. The $\mathrm{Cu}-\mathrm{Sn}$-decorated electrode maintained a high $\mathrm{CE}$ of $97 \%$ over 100 cycles, whereas that of the $\mathrm{Cu}$ foam electrode decreased sharply to below $3 \%$ after 75 cycles (Fig. 3a). Moreover, impedance spectra of $\mathrm{Cu}-\mathrm{Sn}$-decorated electrode revealed smaller interfacial resistance than $\mathrm{Cu}$ foam electrode after 120 cycles (Fig. 3b). The dendrite-free Li deposition induced stable SEI, improving the cycling performance of LMAs. Furthermore, the $\mathrm{LiFePO}_{4}$-based full cell with $\mathrm{Cu}-\mathrm{Sn}$-decorated electrode also exhibited enhanced cycling performance compared to that using the $\mathrm{Cu}$ foam electrode (Fig. 3c). The capacity of full cell with $\mathrm{Cu}-\mathrm{Sn}$ decorated electrode was retained at $85 \mathrm{mAh} \mathrm{g}^{-1}$ with a high CE of $99.5 \%$ after 300 cycles, presenting a capacity retention of $79.4 \%$ while the capacity of full cell with $\mathrm{Cu}$ foam electrode dropped to $20 \mathrm{mAh} \mathrm{g}^{-1}$ with a CE of $98.3 \%$. In comparison with full cell with $\mathrm{Cu}$ foam electrode, the voltage profile of full cell with $\mathrm{Cu}-\mathrm{Sn}$-decorated electrode also shows lower voltage polarization. According to SEM images in Fig. 4, after 300 cycles, the surface of $\mathrm{Cu}$-Sn-decorated $\mathrm{Cu}$ foam electrode was smoother than $\mathrm{Cu}$ foam electrode, and no obvious dendritic and mossy Li could be observed. In terms of the above results, the electrochemical performance of as-prepared 3D skeletons significantly is better than one of recently reported alloy modified skeletons $[15,19]$.
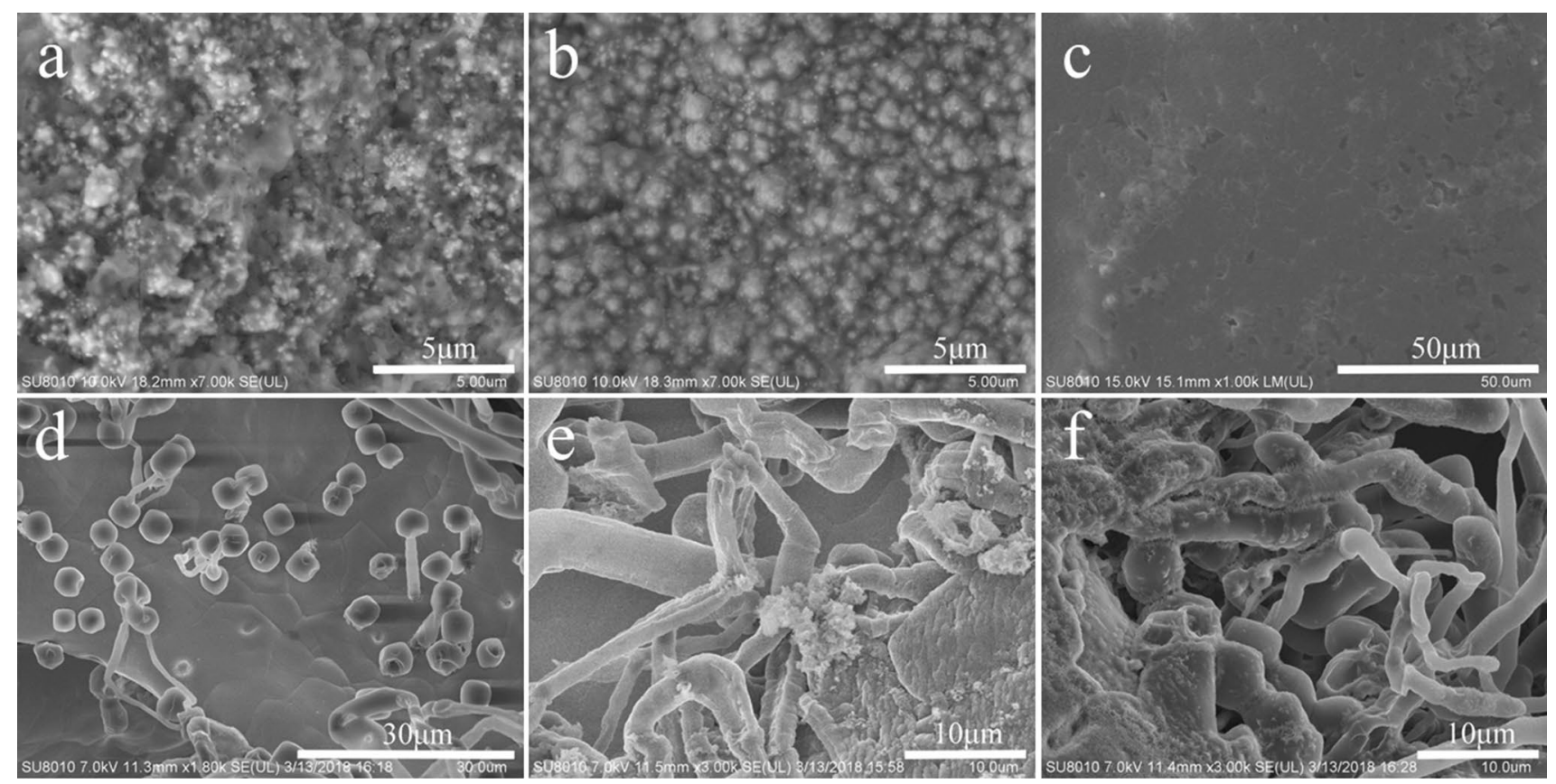

Fig. 2 SEM images of Li deposition on the $\mathrm{Cu}-\mathrm{Sn}$-decorated $\mathrm{Cu}$ foam substrate after a $0.5 \mathrm{mAh} \mathrm{cm}{ }^{-2}, \mathbf{b} 1.5 \mathrm{mAh} \mathrm{cm}^{-2}$, c $3 \mathrm{mAh} \mathrm{cm} \mathrm{m}^{-2}$ of Li

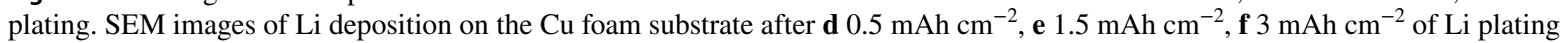



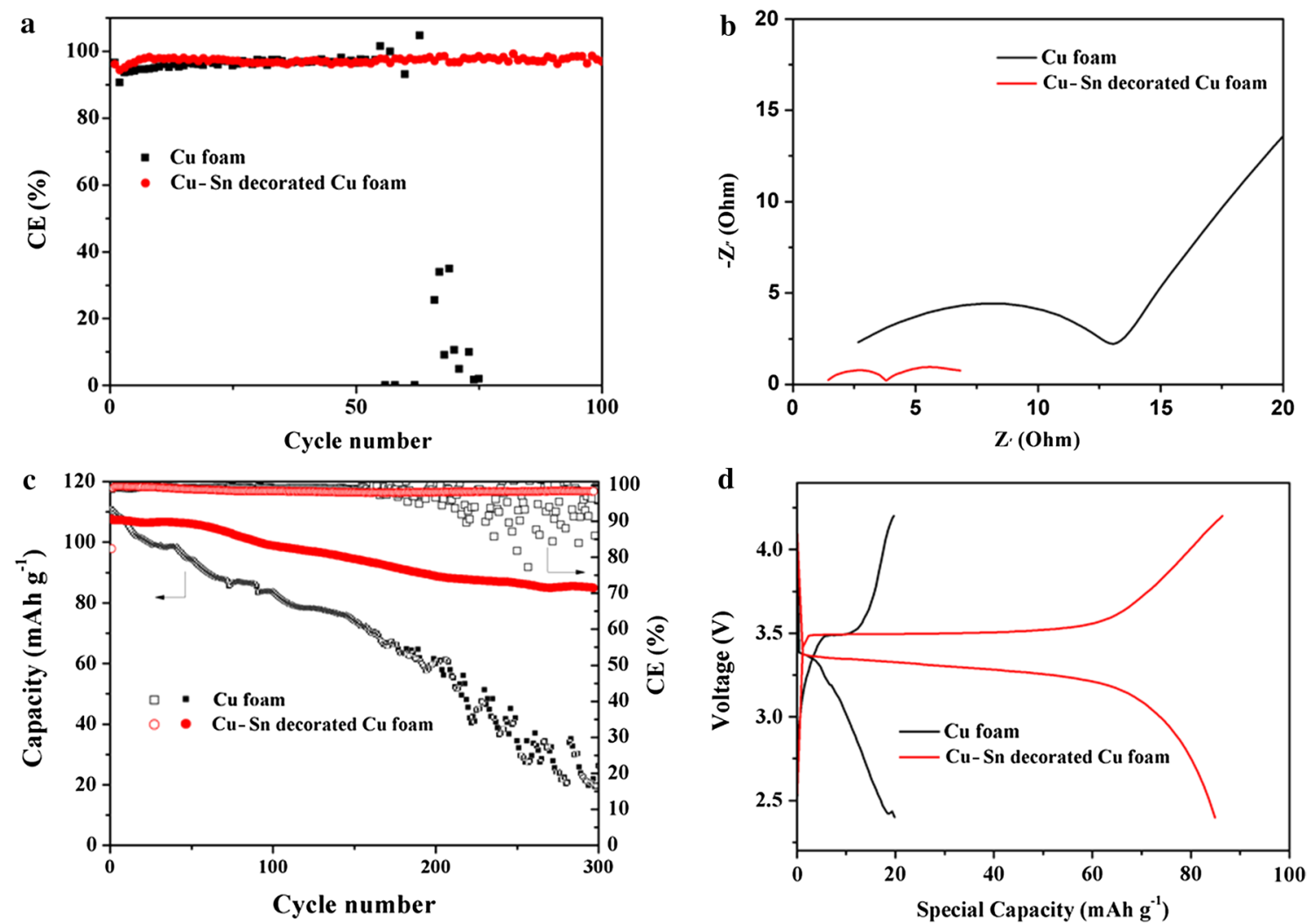

Fig. 3 a Coulombic efficiency $(\mathrm{CE})$ of $\mathrm{Cu}$ foam and $\mathrm{Cu}-\mathrm{Sn}$-decorated $\mathrm{Cu}$ foam. $\mathbf{b}$ Impedance spectra of $\mathrm{Cu}$ foam and $\mathrm{Cu}-\mathrm{Sn}$-decorated $\mathrm{Cu}$ foam at $1.5 \mathrm{~mA} \mathrm{~cm}{ }^{-2}$ after 120 cycles. c Electrochemical performance of full cell with $\mathrm{LiFePO}_{4}$ cathodes using $\mathrm{Cu}$ foam and $\mathrm{Cu}-\mathrm{Sn}-\mathrm{decorated} \mathrm{Cu}$ foam as current collector at $5 \mathrm{C}$, d their voltage profiles for the 300th cycle
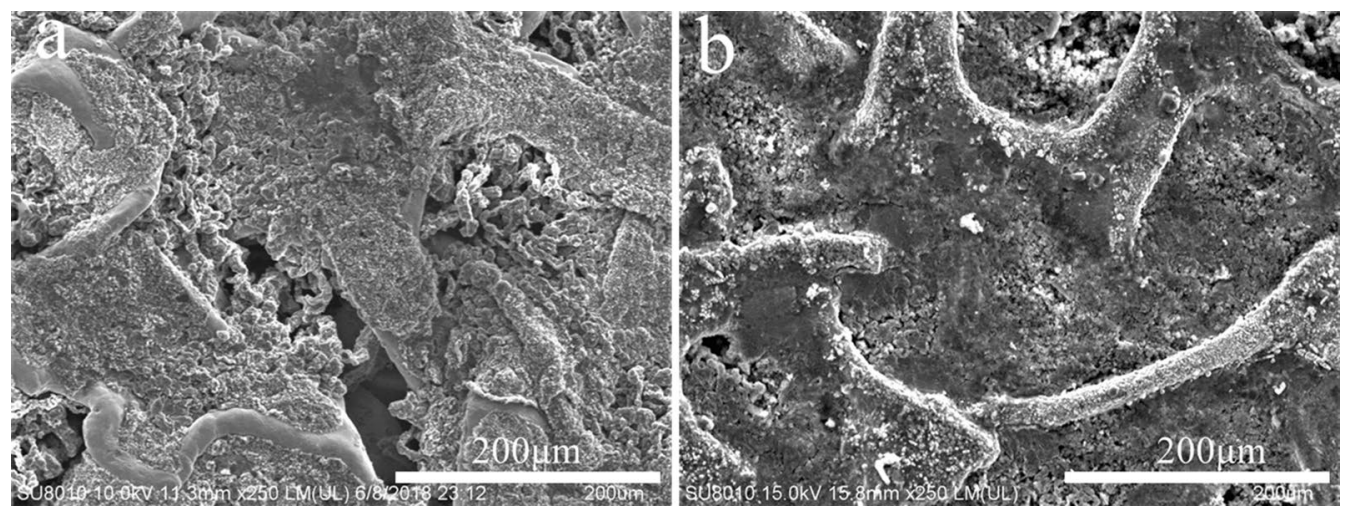

Fig. 4 SEM morphologies of $\mathbf{a} \mathrm{Cu}$ foam/Li anode $\mathbf{b} \mathrm{Cu}-\mathrm{Sn}$-decorated $\mathrm{Cu}$ foam from a full cell with $\mathrm{LiFePO}_{4}$ cathode after 300 cycles

Metallic Sn has definite solubility in lithium metal so that it could generate a solid solution buffer layer before Li metal formation [20], and the Sn (101) face serves as appropriate orientation for enhancing lattice coincidence with the Li (110) plane, improving affinity between substrate and lithium, inducing uniform and dendrite-free $\mathrm{Li}$ deposition $[21,22]$. $\mathrm{Cu}-\mathrm{Sn}$ alloy-coated electrode with high surface area is able to decrease local current density and suppress continued propagation of Li dendrite [23]. Alloy-induced dendrite-free Li plating improves the interfacial stability between $\mathrm{Li}$ and electrolyte and alleviates the formation of inactive $\mathrm{Li}$, enhancing safe and long-life performance for Li metal batteries [24]. 


\section{Conclusion}

In this work, $\mathrm{A} \mathrm{Cu}-\mathrm{Sn}$ alloy-coated current collector was prepared through co-deposition technology for inhibiting $\mathrm{Li}$ dendrites. Sn component of $\mathrm{Cu}-\mathrm{Sn}$ alloy shows high lithiophilicity with $\mathrm{Li}$ and is utilized as heterogeneous medium for $\mathrm{Li}$ deposition. Moreover, highly porous $\mathrm{Cu}-\mathrm{Sn}$ alloy architecture with an increased surface area is designed to reduce local current density during Li plating/stripping. As a result, $\mathrm{Cu}-\mathrm{Sn}$ alloy-coated electrodes exhibit uniform lithium deposition without dendritic formation, high CE, low interfacial resistance, and long cycling life. The LiFePO4-based full cell with the as-prepared $\mathrm{Li}$ anode retained at $85 \mathrm{mAh} \mathrm{g}^{-1}$ with a high CE of $99.5 \%$ after 300 cycles. Surface engineering on current collector offers a promising strategy to structure dendrite-free $\mathrm{Li}$ anode and facilitate the practical application of Li metal batteries.

Acknowledgements This work was financially supported by the National Natural Science Foundation of China (No. 21673051) and the Department of Science and Technology of Guangdong Province, China (No. 2019A050510043).

\section{References}

[1] Y.P. Guo, H.Q. Li, T.Y. Zhai, Adv. Mater. 29, 25 (2017)

[2] S.Q. Shi, J. Gao, Y. Liu, Y. Zhao, Q. Wu, W.W. Ju, C.Y. Ouyang, R. Xiao, J. Chin. Phys. B 25, 24 (2016)

[3] X.B. Cheng, R. Zhang, C.Z. Zhao, Q. Zhang, Chem. Rev. 117, 10403 (2017)

[4] F. Sun, X. He, X. Jiang, M. Osenberg, J. Li, D. Zhou, K. Dong, A. Hilger, X. Zhu, R. Gao, X. Liu, K. Huang, D. Ning, H. Markötter, L. Zhang, F. Wilde, Y. Cao, M. Winter, I. Manke, Mater. Today 27, 21 (2019)

[5] Y. Zhang, W. Lv, Z. Huang, G. Zhou, Y. Deng, J. Zhang, C. Zhang, B. Hao, Q. Qi, Y.B. He, F. Kang, Q.H. Yang, Sci. Bull. 64, 910 (2019)
[6] Y. Guo, Y. Ouyang, D. Li, Y. Wei, T. Zhai, H. Li, Energy Storage Mater. 16, 203 (2019)

[7] L. Chen, Y. Li, S.P. Li, L.Z. Fan, C.W. Nan, J.B. Goodenough, Nano Energy 46, 176 (2018)

[8] X. Ke, Y.F. Cheng, J. Liu, L.Y. Liu, N.G. Wang, J.P. Liu, C.Y. Zhi, Z.C. Shi, Z.P. Guo, A.C.S. Appl, Mater. Interfaces 10, 13552 (2018)

[9] S.H. Wang, Y.X. Yin, T.T. Zuo, W. Dong, J.Y. Li, J.L. Shi, C.H. Zhang, N.W. Li, C.J. Li, Y.G. Guo, Adv. Mater. 29, 1703729 (2017)

[10] C.Z. Sun, Y.P. Li, J. Jin, J.H. Yang, Z.Y. Wen, J. Mater. Chem. A 7, $7752(2019)$

[11] R. Zhang, X. Chen, X. Shen, X.Q. Zhang, X.R. Chen, X.B. Cheng, C. Yan, C.Z. Zhao, Q. Zhang, Joule 2, 764 (2018)

[12] Y. Liu, L. Wang, K. Jiang, S. Yang, J. Alloys Compd. 775, 818 (2019)

[13] H. Ye, Z.J. Zheng, H.R. Yao, S.C. Liu, T.T. Zuo, X.W. Wu, Y.X Yin, N.W. Li, J.J. Gu, F.F. Cao, Y.G. Guo, Angew. Chem. Int. Ed. 58, 1094 (2019)

[14] X. Liang, Q. Pang, I.R. Kochetkov, M.S. Sempere, H. Huang, X. Sun, L.F. Nazar, Nat. Energy 6, 2017119 (2017)

[15] S. Liu, X.Y. Zhang, R.S. Li, L.B. Gao, J.Y. Luo, Energy Storage Mater. 14, 143 (2018)

[16] K. Yan, Z.D. Lu, H.W. Lee, F. Xiong, P.C. Hsu, Y.Z. Li, J. Zhao, S. Chu, Y. Cui, Nat. Energy 1, 8 (2016)

[17] A. Pei, G.Y. Zheng, F.F. Shi, Y.Z. Li, Y. Cui, Nano Lett. 17, 1132 (2017)

[18] Y. Gu, H.Y. Xu, X.G. Zhang, W.W. Wang, J.W. He, S. Tang, J.W. Yan, D.Y. Wu, M.S. Zheng, Q.F. Dong, B.W. Mao, Angew. Chem. Int. Ed. 58, 3092 (2019)

[19] X.B. Cheng, H.J. Peng, J.Q. Huang, F. Wei, Q. Zhang, Small 10, 4257 (2014)

[20] B. Xu, S. Qi, M. Jin, X. Cai, L. Lai, Z. Sun, X. Han, Z. Lin, H. Shao, P. Peng, Z. Xiang, J.E. ten Elshof, R. Tan, C. Liu, Z. Zhang, X. Duan, J. Ma, Chin. Chem. Lett. (2019)

[21] J. Liao, W. Ni, C. Wang, J. Ma, Chem. Eng. (2019). https://doi. org/10.1016/j.cej.2019.123489

[22] D. Wu, C. Wang, M. Wu, Y. Chao, P. He, J. Ma, J. Energy Chem. 43, 24 (2020)

[23] J. Duan, W. Wu, A.M. Nolan, T. Wang, J. Wen, C. Hu, Y. Mo, W. Luo, Y. Huang, Adv. Mater. 31, 1807243 (2019)

[24] X. Zheng, P. Li, Z. Cao, W. Luo, F. Sun, Z. Wang, B. Ding, G. Wang, Y. Huang, Small 15, 1902688 (2019) 